\title{
Frontotemporal lobar degeneration: old knowledge and new insight into the pathogenetic mechanisms of tau mutations
}

\author{
Giacomina Rossi ${ }^{\star}$ and Fabrizio Tagliavini \\ Division of Neurology V and Neuropathology, Fondazione IRCCS Istituto Neurologico Carlo Besta, Milano, Italy
}

Frontotemporal lobar degeneration (FTLD) is a group of heterogeneous neurodegenerative diseases which includes tauopathies. In the central nervous system (CNS) tau is the major microtubule-associated protein (MAP) of neurons, promoting assembly and stabilization of microtubules (MTs) required for morphogenesis and axonal transport. Primary tauopathies are characterized by deposition of abnormal fibrils of tau in neuronal and glial cells, leading to neuronal death, brain atrophy and eventually dementia. In genetic tauopathies mutations of tau gene impair the ability of tau to bind to MTs, alter the normal ratio among tau isoforms and favor fibril formation. Recently, additional functions have been ascribed to tau and different pathogenetic mechanisms are then emerging. In fact, a role of tau in DNA protection and genome stability has been reported and chromosome aberrations have been found associated

Edited by:

Carmen Giordano,

Politecnico di Milano, Italy

Reviewed by:

Federica Agosta,

Vita-Salute San Raffaele University,

Italy

Ramesh Kandimalla,

Texas Tech University, USA

*Correspondence:

Giacomina Rossi,

Division of Neurology $V$ and Neuropathology, Fondazione IRCCS Istituto Neurologico Carlo Besta, Via Celoria 11, 20133 Milano, Italy grossi@istituto-besta.it

Received: 04 July 2015 Accepted: 22 September 2015 Published: 14 October 2015

Citation:

Rossi G and Tagliavini F (2015) Frontotemporal lobar degeneration: old knowledge and new insight into the pathogenetic mechanisms of tau mutations.

Front. Aging Neurosci. 7:192. doi: 10.3389/fnagi.2015.00192 with tau mutations. Furthermore, newly structurally and functionally characterized mutations have suggested novel pathological features, such as a tendency to form oligomeric rather than fibrillar aggregates. Tau mutations affecting axonal transport and plasma membrane interaction have also been described. In this article, we will review the pathogenetic mechanisms underlying tau mutations, focusing in particular on the less common aspects, so far poorly investigated.

Keywords: tau, MAPT, mutation, tauopathies, frontotemporal lobar degeneration, pathogenetic mechanisms

\section{Introduction}

Alzheimer (1907) described the existence in brain tissue of intracellular neurofibrillary tangles associated with extracellular plaques and only a few years later the presence of intracellular inclusions alone in a different case of dementia (Alzheimer, 1911).

It was not until the 1980s that the protein constituting these deposits was identified as the microtubule-associated tau protein (Goedert et al., 1988; Wischik et al., 1988). Tau protein had been previously identified in 1975 as a new microtubule-associated protein (MAP) with a relatively low molecular weight with respect to high molecular weight MAP-1 and MAP-2 (Weingarten et al., 1975).

Primary tauopathies belong to the frontotemporal lobar degeneration (FTLD) group of degenerative diseases. FTLD are heterogeneous from a clinical, pathological and genetic point of view. Clinically, they are characterized by behavior, executive and language impairment, giving rise to behavioral variant of frontotemporal dementia (bvFTD), semantic dementia (SD) and progressive non-fluent aphasia (PNFA), often associated with parkinsonism or motor 
neuron disease (MND). Pathologically, deposits of different misfolded proteins are found in brain tissue: tau, transactive response DNA binding protein 43, fused-in-sarcoma, and dipeptide-repeat proteins. The main mendelian genes so far linked to FTLD include genes coding for microtubuleassociated protein tau (MAPT) and progranulin (GRN), and Chromosome 9 Open Reading Frame 72 (C9ORF72) gene, with other genes being more rarely associated (Rademakers et al., 2012; Mori et al., 2013).

Primary tauopathies are defined by the presence in neuronal and glial cells of deposits of misfolded, insoluble and hyperphosphorylated tau proteins. Clinically, they fall into the spectrum of FTLD, presenting with bvFTD, SD and PNFA; in addition they also can present with progressive supranuclear palsy (PSP) and corticobasal syndrome (CBS). Tauopathies can be sporadic or familiar, genetically determined by mutations in MAPT. As a MAP, the role of tau is to promote microtubule (MT) assembly and stabilization and regulate MT dynamics (Goode and Feinstein, 1994; Gustke et al., 1994; Trinczek et al., 1995). A single MAPT gene gives rise to six tau isoforms by alternative RNA splicing of exons 2, 3 and 10. The binding region to MT (microtubule-binding domain, MBD) is in the C-terminal half of tau and is constituted by either 3 repeats ( $3 \mathrm{R}$ tau) or, if exon 10 is included, 4 repeats (4R tau) of 31-32 aminoacids. Alternative splicing of tau is developmentally regulated and in the adult human brain all the six isoforms are expressed, with $3 \mathrm{R}$ tau and $4 \mathrm{R}$ tau represented at about the same level $(4 \mathrm{R} / 3 \mathrm{R}$ ratio $\cong 1$; Goedert et al., 1989a,b). Since $4 \mathrm{R}$ and $3 \mathrm{R}$ tau isoforms assume complex and distinct MT binding structures (Goode et al., 2000) and regulate dynamic instability of MT in different ways (Levy et al., 2005), with $4 \mathrm{R}$ tau isoforms having a higher ability to promote MT polymerization (Goedert and Jakes, 1990), any imbalance of the $4 \mathrm{R} / 3 \mathrm{R}$ ratio is supposed to cause MT misregulation and a tendency of the isoforms in excess to produce fibrillar aggregation.

While in Alzheimer's disease (AD) tau fibrils are made of all six isoforms (Goedert et al., 1992), in primary tauopathies some isoforms predominate, depending on the neuropathological phenotype. In Pick's disease (PiD) 3R tau isoforms are present, while in PSP and corticobasal degeneration (CBD) $4 \mathrm{R}$ tau isoforms are found. In genetic tauopathies, $4 R, 3 R$ or a combinations of $4 \mathrm{R}$ and $3 \mathrm{R}$ tau isoforms are present (Dickson et al., 2011).

Tau is a highly phosphorylated protein: there are 79 putative phosphorylation sites on the protein and at least 30 have been demonstrated to be actually phosphorylated. The phosphorylation state is the main system which regulates tau binding to MT: non phosphorylated sites lead to a stronger binding, whereas phosphorylation decreases the binding, making MT more unstable (Buée et al., 2000). Hyperphosphorylation characterizes abnormal tau present in all the taupathies (Buée et al., 2000; Spires-Jones et al., 2009).

Although tau is abundantly expressed in central nervous system and is the major MAP of neurons, it is also present in several non-neural tissues, such as fibroblasts and lymphocytes (Ingelson et al., 1996; Thurston et al., 1996; Rossi et al., 2008a).
In 1990s, linkage analysis in families affected by frontotemporal dementia with parkinsonism (FTDP) and pathologically characterized by tau deposits in neuronal and glial cells indicated that the candidate gene lied at 17q21-22, where MAPT is located, and in 1998 sequencing analysis finally revealed pathological mutations of MAPT (FTDP linked to chromosome 17-tau, FTDP-17T). Some missense mutations were recognized as causative based on the highly conserved site, the absence in control subjects and the segregation with the disease in the FTDP-17T families: G272V, P301L and R406W mutations (Hutton et al., 1998). A different kind of mutations was also found in other families: base pair substitutions in the $5^{\prime}$ splice site of exon 10 (intron 10). They segregated with the disease and were not present in control subjects (Hutton et al., 1998; Spillantini et al., 1998). Several further missense and splice-site mutations, as well as in-frame small deletions, were later found. All the mutations are transmitted with a dominant pattern of inheritance, with rare exceptions. Penetrance is usually complete, with a few exceptions (van Herpen et al., 2003; Rossi et al., 2008b). Afterwards, different kinds of mutations, such as gross deletions or insertions, regulatory and risk factors have been found. Complete mutation databases to refer to are the Human Gene Mutation Database (Stenson et al., 2014) and the AD\&FTD Mutation Database (Cruts et al., 2012).

We present here an overview of all tau mutations so far described and the underlying pathological mechanisms. Figure 1 represents an overall view of all tau mutations whose pathogenicity is definite/probable by means of genetic, neuropathological or functional data; mutations with peculiar features, mutations uncharacterized but present only in affected subjects and mutations considered as risk factors are also indicated.

\section{Mutations Affecting MT Polymerization and/or Fibrillar Aggregation}

\section{Mutations Within or near the MBD and in C-Terminal Domain Missense Mutations}

The MBD (exons 9-12; aminoacid 244-368; Mukrasch et al., 2005 ) is the region essential for the primary function of tau, that is MT binding, polymerization and dynamics regulation. By means of in vitro affinity or polymerization assays of recombinant tau protein with monomeric tubulin, most of missense mutations localized in MBD have been demonstrated to confer a reduced ability to interact with tubulin, slowing and decreasing MT formation (Hasegawa et al., 1998; Hong et al., 1998; Figure 2A). This "loss of function" pathological mechanism can lead to cytoskeleton disruption, affecting physiological cell functions (Iqbal et al., 2009).

G389R and $\mathrm{N} 410 \mathrm{H}$ mutations have a reduced ability to promote MT polymerization (Murrell et al., 1999; PickeringBrown et al., 2000; Kouri et al., 2014) although localized outside the repeats of $\mathrm{MBD}$, in the C-terminal domain (exon 13). However, this region is highly conserved across species, is close to 


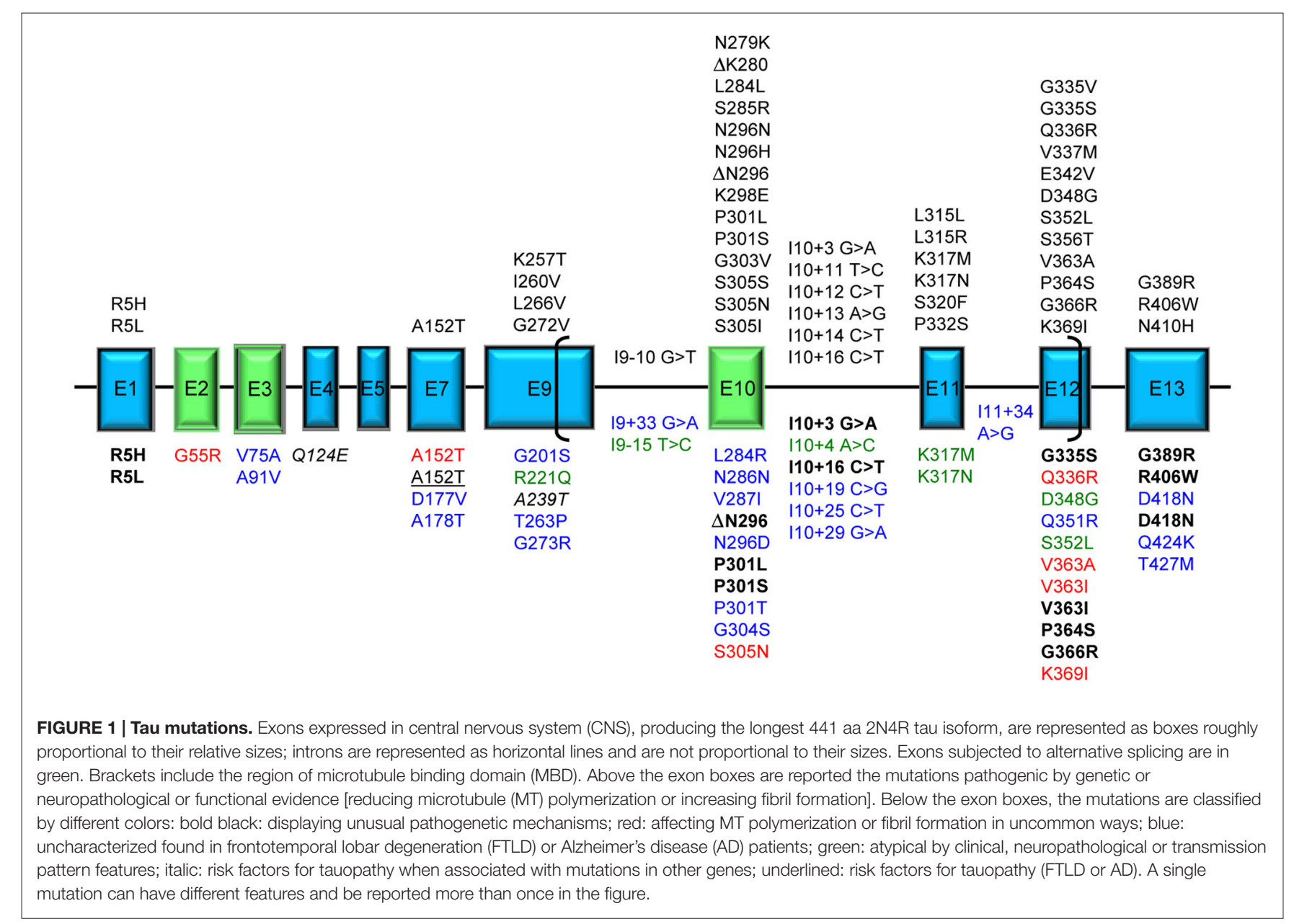

MDB and, most importantly, intramolecular interactions among different tau regions, including C-terminal and $\mathrm{N}$-terminal domains and MBD, have been reported (Jeganathan et al., 2006; Mukrasch et al., 2009). Thus, mutations in C-terminal domain may influence MT formation.

MBD contains two short sequences responsible for the acquisition of $\beta$-structure necessary for tau aggregation into pathological fibrils (Mukrasch et al., 2005). Thus, several missense mutations, depending on their position, also increase the propensity of tau to aggregate into fibrils (Barghorn et al., 2000; von Bergen et al., 2001) (Figure 2B), although some pathogenic mutations did not show this effect (Neumann et al., 2001; Yoshida et al., 2002; Rossi et al., 2012). Fibrillar burden represents a "gain of function" pathological mechanism, with aggregated tau being detrimental to cell function (Spillantini and Goedert, 2013).

Some mutations (V337M, G272V and P301L) have been shown to make tau a more favorable substrate for phosphorylation by brain protein kinases (Alonso et al., 2004). This in turn promotes the reduced binding to MT and the self-aggregation (Alonso et al., 2010). In fact V337M, G272V and P301L have both a reduced binding to MT an increased propensity to aggregation
(Hasegawa et al., 1998; Barghorn et al., 2000; Chang et al., 2008).

R406W mutation, in the C-terminal domain, showed contradictory features: it appeared to have a reduced ability to promote MT binding in in vitro assays (Hasegawa et al., 1998; Hong et al., 1998) but non in a microinjected-cell system (Bunker et al., 2006). It was reported to favor tau phosphorylation in an in vitro system (Alonso et al., 2004) and to decrease it in cellular systems (Vogelsberg-Ragaglia et al., 2000). It has an ability to aggregation similar to wt tau (Chang et al., 2008). Anyway, this mutation showed peculiar pathological mechanisms (see below) that are perhaps the most relevant to neurodegeneration.

\section{Intron 10 Splicing Mutations}

These mutations are located at the $5^{\prime}$ splice site of exon 10 , that is within the first bases of intron 10. A RNA stem-loop structure possibly involved in regulating the alternative splicing of exon10 was predicted (Hutton et al., 1998) and afterwards the threedimensional structure of this region was determined (Varani et al., 1999), showing an upper and lower stem with an apical loop. This structure is involved in regulating alternative splicing of exon 10 presumably by hampering the U1 snRNP binding to the site. Blocking U1 snRNP binding would result in failure 


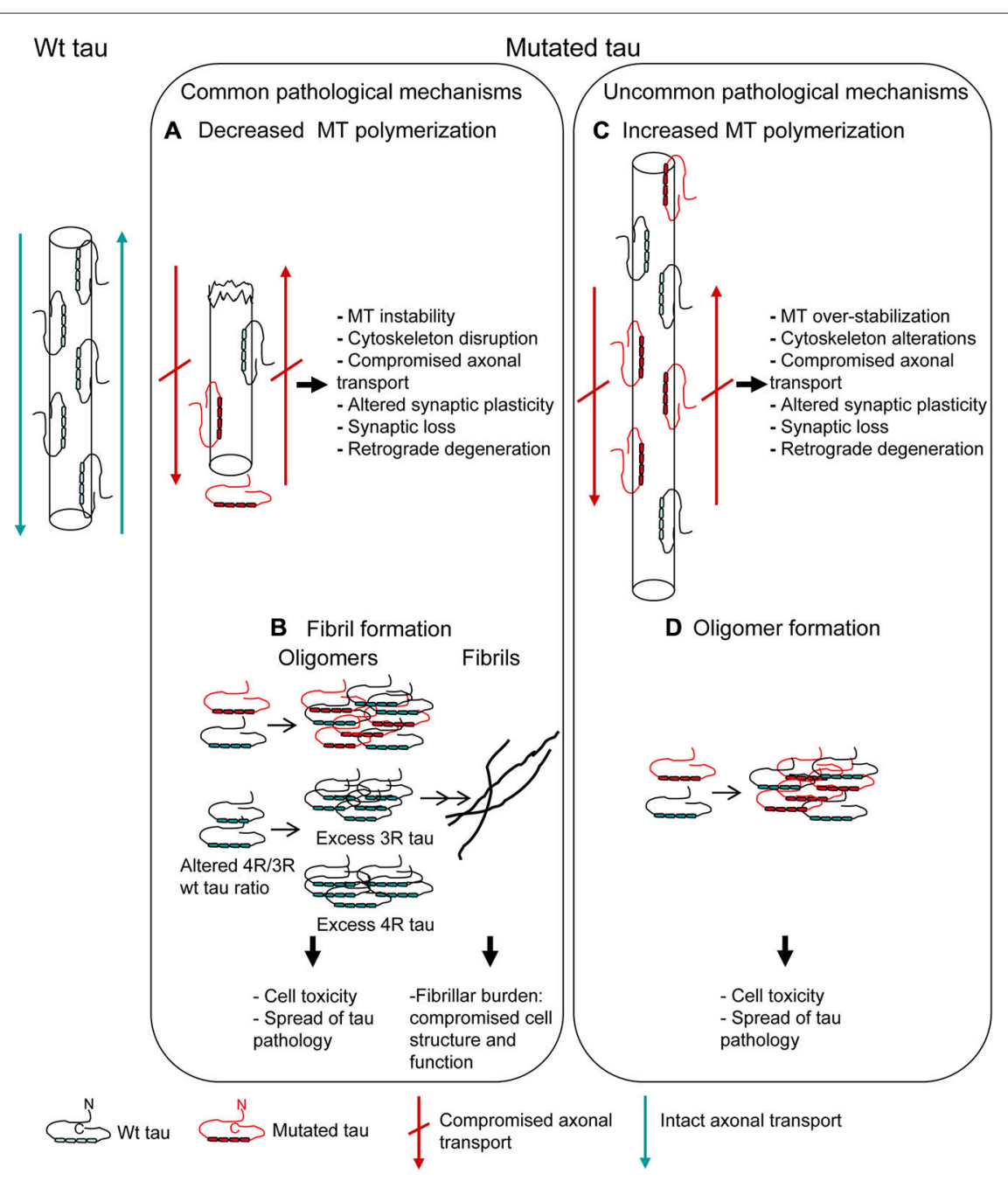

FIGURE 2 | Mutations affecting MT polymerization and/or fibrillar aggregation. Pathogenetic mechanisms underlying tau mutations are depicted. Most of tau mutations reduce the protein ability to promote MT polymerization (A) and/or increase the propensity to aggregate into fibrils (B) ("Common pathological mechanisms"). However, a few tau mutations act in the opposite way, increasing MT polymerization (C) and/or decreasing the propensity to aggregate (D) (“Uncommon pathological mechanisms"). Alterations of MT dynamics, both as destabilization or over-stabilization, may anyway lead to cell degeneration. Oligomer toxicity (interaction with cell membrane, calcium uptake, mithocondrial dysfunction) is now widely confirmed; fibrillar aggregation, even if it might be considered as an attempt by the cell to sequester and neutralize oligomer toxicity, is however a structural and functional burden to cell.

to include exon 10 and lead to skipping of this exon (Hutton et al., 1998). The splicing mutations, located in the upper stem (Spillantini and Goedert, 2000), destabilize the structure, causing a more frequent usage of the $5^{\prime}$ splice site and an increased inclusion of exon 10 in the mRNA, with an overproduction of $4 \mathrm{R}$ tau transcripts and the imbalance of $4 \mathrm{R} / 3 \mathrm{R}$ tau isoforms ratio. The excess of $4 \mathrm{R}$ tau isoforms leads to their accumulation in the cytoplasm followed by formation of fibrillar deposits (Buée et al., 2000).

\section{Silent Mutations and Missense Mutations Affecting Exon 10 Splicing}

These mutations can be located either in the stem-loop structure (S305S, S305N, S305I), producing the same effect as the intron 10 splicing mutations (Hasegawa et al., 1999; Stanford et al., 2000;
Kovacs et al., 2008), or within regulatory elements (enhancers or silencers) in exon 10 (L284L, N286N, N296N; N279K, N296H) affecting exon 10 splicing in a cys-acting manner.

N279K and L284L mutations strenghten two different regions of an enhancer, both resulting in an increased inclusion of exon 10 that is an increase of $4 \mathrm{R}$ tau transcripts (D'Souza et al., 1999; Hasegawa et al., 1999; D'Souza and Schellenberg, 2002). N296N and N296H mutations are supposed to disrupt a silencer (D'Souza and Schellenberg, 2002) or, alternatively, to create a new enhancer (Grover et al., 2002), with the same result of increasing $4 \mathrm{R}$ tau transcripts. $\mathrm{N} 286 \mathrm{~N}$ mutation was supposed to be pathological in the same way (Rohrer et al., 2009).

Some of the missense mutations were also reported to affect protein function. N279K mutation was described to reduce MT polymerization by some authors (Barghorn et al., 2000) 
but not by others (D'Souza et al., 1999; Hasegawa et al., 1999) and to increase the self-aggregation into fibrils (Barghorn et al., 2000). N296H mutation was described to reduce MT polymerization (Grover et al., 2002); the increase of fibril formation is controversial (Grover et al., 2002; Yoshida et al., 2002).

Recently, $\mathrm{N} 410 \mathrm{H}$ mutation in exon 13 was reported to increase the $4 \mathrm{R} / 3 \mathrm{R}$ tau mRNA ratio. The increase of $4 \mathrm{R}$ tau mRNA had also been previously reported for the E342V tau mutation in exon 12 (Lippa et al., 2000). This raises the question of how mutations localized outside exon 10/intron 10 can alter the exon 10 splicing. Unknown regulatory elements (enhancers/silencers) may possibly exist in different regions of $M A P T$ gene.

\section{Microdeletions}

Two in-frame microdeletions involving each a single codon have been described: $\Delta \mathrm{N} 296$ e $\Delta$ K280. $\Delta \mathrm{N} 296$ mutation was consistently reported to reduce MT polymerization, while increasing of fibril formation and effect on exon 10 splicing were controversial (Grover et al., 2002; Yoshida et al., 2002).

Thus, it has to be taken into account the fact that some mutations (N279K, $\mathrm{N} 296 \mathrm{H}$ and $\Delta \mathrm{N} 296)$ can lead to an overproduction of tau $4 \mathrm{R}$ transcripts that however, because of the presence of the mutation, has a lower ability to promote MT polimerization.

$\Delta \mathrm{K} 280$ is a very peculiar and puzzling mutation. This deletion (the deletion is of an AAG that actually can be either at codon 280 or 281 , thus the mutation may be named $\Delta \mathrm{K} 280$ or $\Delta \mathrm{K} 281$ ) in exon 10 was first described by Rizzu et al. (1999) in a patient affected by FTD. They also showed that recombinant mutated protein had a dramatically reduced ability to promote MT assembly. The relevance of this codon to MT affinity and dynamic instability had already been reported in in vitro studies some years before (Goode and Feinstein, 1994; Trinczek et al., 1995).

Furthermore, tau carrying $\Delta \mathrm{K} 280$ mutation is highly fibrillogenic and has been used as a model of tau aggregation, even in absence of aggregation inducers such as heparin (Barghorn et al., 2000; von Bergen et al., 2001; Larini et al., 2013).

However, in addition, $\Delta \mathrm{K} 280$ mutation nearly abolished the exon 10 splicing in vitro, leading to an overproduction of 3R tau isoforms (D’Souza et al., 1999), presumably disrupting an enhancer element (D'Souza and Schellenberg, 2002). The preponderance of $3 \mathrm{R}$ tau was confirmed by neuropathological examination (van Swieten et al., 2007; Momeni et al., 2009). Since all the others pathogenic tau mutations affecting exon 10 splicing increase $4 \mathrm{R}$ tau, $\Delta \mathrm{K} 280$ is a rather peculiar mutation. It can only be present in $4 \mathrm{R}$ tau, being in exon 10 . Thus, the in vitro described pathological effects on MT and tau aggregation can only be accomplished by mutated $4 \mathrm{R}$ tau. However in vivo mostly $3 \mathrm{R}$ tau is present, raising some doubts about the pathogenicity of this mutation. Possible explanations of its pathogenicity may be that: (i) even the very small amount of highly fibrillogenic $\Delta \mathrm{K} 280$ $4 \mathrm{R}$ tau is sufficient to begin tau deposition and sequester wt $3 \mathrm{R}$ or
4R tau, altering MT dynamics and (ii) overproduction of 3R tau leads to accumulation of this isoform into fibrillar deposits.

\section{Mutations Atypical by Clinical, Neuropathological or Transmission Pattern Features}

A family affected by lower MND and respiratory failure was described (Di Fonzo et al., 2014) in which D348G mutation (exon 12) segregated with the disease with a dominant pattern.

Neuropathological examination disclosed pathological tau deposits in hippocampus and motor neurons. D348G mutation seemed not to alter the ability of tau to bind to MT, at variance with the majority of the other mutations localized in the MBD. However this result is based on the evaluation of relative amounts of acetylated/tyrosinated tubulin and on a MT-binding assay in transfected cells which may not be comparable to the in vitro MT polymerization assay used to study the other mutations. The latter assay may in fact be more sensitive and reveal minor differences (Hasegawa et al., 1998; Hong et al., 1998).

A mutation very near to D348G was reported, S352L, interestingly displaying a similar clinical phenotype of respiratory failure, despite the different age of onset, and an atypical neuropathological phenotype (Nicholl et al., 2003). Mutated protein showed a reduced ability to promote MT polymerization and an increased propensity to aggregate. This mutation was transmitted with a recessive pattern of inheritance, the only example for MAPT and one of the very few cases in neurodegenerative diseases.

Another unique case in MAPT genetics was the finding of a family with compound heterozygous mutations $\mathrm{I} 10+4 \mathrm{~A}>\mathrm{C}$; I9 - 15 T > C (Anfossi et al., 2011). The heterozygous condition was associated with normal phenotype and did not alter the R4/R3 tau ratio, while the compound heterozygous state was linked to FTD and increased R3 tau isoforms both in vitro and at neuropathological examination, where a Pick-like picture was shown.

$\mathrm{I} 10+4 \mathrm{~A}>\mathrm{C}$ mutation may be in a position not so critical to strongly influence exon 10 splicing; similarly, although the I9 - $10 \mathrm{G}>\mathrm{T}$ mutation was reported, segregating with FTD and increasing 4R tau isoforms (Malkani et al., 2006), I9 - $15 \mathrm{~T}>\mathrm{C}$ mutation may be in a less critical position and have scarce effect. Only the contemporary presence of the two mutations surrounding exon 10 could significantly alter its splicing, supposing trans-acting effects on splicing machinery.

The increase of $3 \mathrm{R}$ tau isoforms in association with tau mutations is not frequent: to date, only $\Delta \mathrm{K} 280, \mathrm{I} 10+19$ C > G (Stanford et al., 2003) and this compound heterozygous mutations showed this effect. Most of splicing affecting mutations, in contrast, produce an increase of $4 \mathrm{R}$ tau isoforms. However, the imbalance between $4 \mathrm{R}$ and $3 \mathrm{R}$ tau isoforms appears to be pathological in any case.

$\mathrm{K} 317 \mathrm{M}$ is the only tau mutation so far reported causing FTLD and MND (Zarranz et al., 2005). In fact, FTLD-MND is mostly associated with mutations in C9ORF72 gene (Rohrer and Warren, 2011). K317N is the first mutation to date reported associated with the recently defined pathological entity globular glial tauopathy (GGT; Tacik et al., 2015). After reviewing the 
neuropathological study, the Authors suggest that K317M also may be classified as GGT.

R221Q mutation was identified in a sporadic patient diagnosed with Dementia with Lewy bodies (DLB): this is the first case of probable DLB carrying a MAPT mutation (Meeus et al., 2012). However, the mutation is outside the MBD, and no functional studies were performed, thus its pathogenetic character is so far not proven.

\section{Missense Mutations in the N-Terminal Domain}

$\mathrm{R} 5 \mathrm{~L}$ and $\mathrm{R} 5 \mathrm{H}$ mutations (exon 1) were detected in patients affected by PSP and late-onset frontotempral dementia, respectively (Hayashi et al., 2002; Poorkaj et al., 2002). Both mutations affected MT assembly and $\mathrm{R} 5 \mathrm{H}$, in addition, showed an increased propensity to aggregation. G55R is the first mutation found in the alternatively spliced exon 2 . Similarly to R5L and R5H mutations, it affects MT assembly, although with a unusual mechanism (see below).

How a mutation in N-terminal domain may affect the functionality and aggregation properties of the MBD can be speculated. While it has been showed that flanking regions of MBD act as "targeting" domains and the 3 or 4 repeats act as "catalytic" domains for MT polymerization (Trinczek et al., 1995), the N-terminal domain did not appear to contribute. However, as already discussed for C-terminal mutations, intramolecular interactions among C-terminal and N-terminal domains and MBD have been reported (Jeganathan et al., 2006; Mukrasch et al., 2009). Thus, these N-terminal mutations may affect $\mathrm{MBD}$ properties. Additional hypotheses about the pathological effects of $\mathrm{R} 5 \mathrm{~L}$ and $\mathrm{R} 5 \mathrm{H}$ mutations have been advanced after the interaction of tau with the dynactin complex was demonstrated (Magnani et al., 2007; see below).

\section{Mutations Affecting MT Polymerization and/or Fibrillar Aggregation in an Uncommon Way}

Usually, tau mutations affecting the interaction with MT cause a reduced ability to promote MT polymerization and the mutations affecting tau self-aggregation lead to fibril formation. However a few mutations showed different abnormal features (Figures 2C,D).

V363I mutation has been associated with several FTLD clinical phenotypes and also with an uncommon phenotype such as posterior cortical atrophy (Rossi et al., 2014a). Neuropathological examination is unfortunately missing, but in vitro functional and structural analysis revealed peculiar and very likely pathological features. V363I mutation showed a greater ability to promote MT polymerization, consisting in both a higher polymerization rate and the formation of longer tubulin polymers (Rossi et al., 2014a; Figure 2C). The increased ability of tau to induce MT polymerization had been previously reported for Q336R and S305N tau mutations (Pickering-Brown et al., 2004), but the effect was small or unclear and not further investigated. G55R mutation was recently described to increase MT polymerization, although MT length was smaller than for wt tau (Iyer et al., 2013). Increased MT polymerization can be considered as a "gain of function" pathological mechanism altering the tightly regulated MT dynamics, which is necessary for physiological neuronal functions such as axonal transport and synapse plasticity. In fact, excessive MT polymerization, although due to excess of wt tau rather than to mutated tau, produced axonal dilations and motor impairment in a transgenic mouse model (Spittaels et al., 1999), which could be rescued by reducing the ability of tau to bind to and promote MT polymerization (Spittaels et al., 2000).

V363I mutation showed a dramatically reduced tendency to fibrillogenesis, producing instead oligomers that persist over long incubation times without any fibrils production; similar properties were shown by V363A mutation (Rossi et al., 2014a; Figure 2D). Other two tau mutations previously showed a similar behavior: K369I mutation and the risk factor A152T, which however caused the formation of shorter than wt fibrils and not merely oligomers (Neumann et al., 2001; Coppola et al., 2012). Toxicity of tau oligomers rather than, or in addition to, tau fibrils is now emergin. Both extracellular (Gómez-Ramos et al., 2008; Lasagna-Reeves et al., 2010) and intracellular (Iliev et al., 2006) tau oligomers were toxic to neuroblastoma cells. Tau oligomers have been isolated from brains affected with $\mathrm{AD}$ (Maeda et al., 2006) and a correlation between the presence of tau oligomers and memory loss was described in animal models (Berger et al., 2007). In addition, tau oligomers are considered as responsible for the spread of tau pathology (Gerson and Kayed, 2013). Thus, tau oligomer formation and persistence may be considered a pathological feature of mutated tau protein.

\section{Genetic Risk Factors for Tauopathies}

Genetic risk factors are sequence variations that can be present both in healthy controls and affected subjects but with significantly different proportions, reflecting their character predisposing to disease. They can be localized in coding regions or in regulatory regions, affecting different features of a gene.

\section{H1/H2 MAPT Haplotypes}

After the first identification of the significant allelic association of a MAPT polymorphism with PSP (Conrad et al., 1997), the allelic association was subsequently extended to a series of polymorphisms covering the entire MAPT coding region, allowing the definition of the haplotypes $\mathrm{H} 1 / \mathrm{H} 2$ (Baker et al., 1999). A more extended haplotype spanning promoter, intronic and coding regions of MAPT was then described and $\mathrm{H} 1$ haplotype was found associated with PSP and CBD (Pittman et al., 2005; Cruchaga et al., 2009). Chromosome 17q21, where $M A P T$ is located, is characterized by a peculiar genomic architecture. In fact, the presence of low-copy repeats is at the basis of the $900 \mathrm{~kb}$ inversion that resulted in the formation of common H1 and H2 haplotypes (Cruts et al., 2005; Stefansson et al., 2005).

Some of the haplotype polymorphisms were characterized for their possible functional significance in the context of the disease (Figure 3A).

- H1c sub-haplotype apparently gives rise to an increased expression of tau, mostly $4 \mathrm{R}$ tau transcripts (Myers et al., 2007). Notably, H1c haplotype was associated with increased 


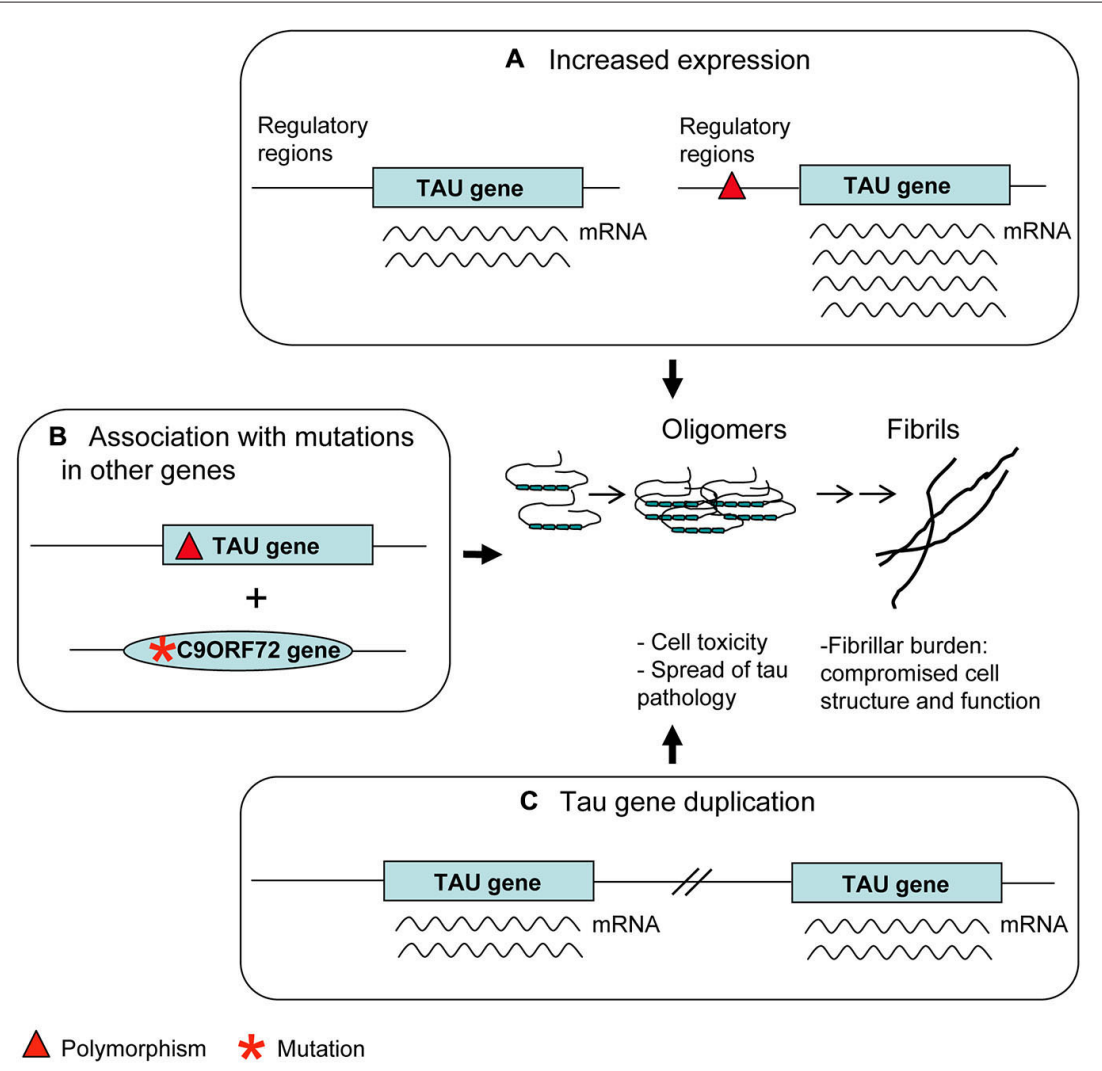

FIGURE 3 | Genetic risk factors. Polymorphisms in regulatory regions (A) as well as Tau gene duplication (C) may account for an increased tau expression. This is considered a disease risk factor because of the possible tendency of tau molecules in excess to aggregate into oligomers and fibrils. Some apparently benign tau polymorphisms (B) can produce an overt tau pathology only in association with mutations present in other genes relevant to neurodegenerative diseases (C9ORF72 is an example).

risk for PSP (Pittman et al., 2005), in which 4R tau deposits are present, although these results were not replicated (Cruchaga et al., 2009).

- The 5'-upstream variant rs1880753, localized at $160 \mathrm{~Kb}$ from transcription start site of MAPT, is associated with PSP and $\mathrm{CBD}$; this variant is in a conserved sequence across mammals which is a potential binding site for YY1 and BNCF/BNC transcription factors (Cruchaga et al., 2009). Similarly, the $-221 \mathrm{C}>\mathrm{G}$ and $-44 \mathrm{~A}>\mathrm{G}$ polymorphisms in the promoter region, associated with PSP, could affect binding sites for transcription factors (de Silva et al., 2001).

- The $+347 \mathrm{G}>\mathrm{C}$ polymorphism in the promoter up-regulates $M A P T$ expression in an in vitro assay (Sun and Jia, 2009).

Deregulated and in particular increased expression of tau may lead to the risk of a pathological accumulation and deposition of the protein in its fibrillar form, as confirmed by several studies on animal models of tauopathies in which tau is over-expressed (Götz et al., 2007).

\section{Missense Mutations}

Nearly all missense mutations inside or near the MBD have been demonstrated to be pathogenic and benign polymorphisms in this region of MAPT are so far absent, with the exception of V300I (exon 10). This is the only polymorphism described in MBD (Guerreiro et al., 2010); however it can not be excluded that the subject in whom it was detected could be a presymptomatic case, as no details about this individual are available. All the remaining missense mutations in this region must be considered risk factors or mutations not well characterized.

A239T mutation (exon 9) is a very peculiar case. It was first described in a patient affected by FTD with taunegative neuropathology (Pickering-Brown et al., 2002). The finding in the same patient of a null mutation in GRN suggested A239T to be a very rare benign variant (PickeringBrown et al., 2006). However, the possible pathological role of $\mathrm{A} 239 \mathrm{~T}$ was raised again by the interesting finding that another patient carrying the C9ORF72 expansion and the A239T had, at neuropathological examination, a tauopathy overhanging p62 and TDP-43 pathology (King et al., 2013). Thus, A239T mutation may be a risk factor for tauopathy appearing preferably in association with other pathogenetic mutations (Figure 3B). Similar considerations can be made about the Q124E mutation (exon 4), associated with a LRRK2 mutation (Ling et al., 2013). 
A152T mutation (exon 7) has been demonstrated to be a risk factor for tauopathies, both FTLD and AD, based on neuropathological, association and functional studies (Kovacs et al., 2011; Coppola et al., 2012; Jin et al., 2012; Kara et al., 2012). Although this mutation is far from the MBD, it decreased the binding of tau to MT and their polymerization and showed a tendency to form oligomeric aggregates instead of fibrils, raising the hypothesis that other not well characterized regions of tau may be involved in regulating protein function.

Several missense mutations have been exclusively detected in patients affected by FTLD or AD and not in control subjects; some of them are at same codons where different pathogenic mutations had been previously reported (L284R, P301T, N296D). However segregation, neuropathological or functional studies were not performed, so that their pathogenicity was not proven: V75A, A91V (one case of Parkinson disease), D177V, A178T, G201S, T263P, G273R, L284R, N286N, V287I, N296D, P301T, G304S, Q351R, D418N (one case with ataxia and cognitive impairment), Q424K, T427M (Stenson et al., 2014; Cruts et al., 2012; Jin et al., 2012; Kim et al., 2014). Clinical phenotypes other than FTLD, in particular AD phenotype, were sometimes associated with tau mutations. However it was recognized that this was most likely due to misdiagnosis (Cruchaga et al., 2012).

\section{Intronic Mutations}

A few intronic mutations were found whose pathogenicity is uncertain.

$\mathrm{I} 10+29 \mathrm{G}>\mathrm{A}$ segregated with the FTLD phenotype in one family but no tauopathy was present in brain tissue. This mutation had been detected at low frequency in control subjects and later a null GRN gene mutation was found in this family, suggesting $\mathrm{I} 10+29 \mathrm{G}>\mathrm{A}$ to be a benign polymorphism (Stanford et al., 2003; Pickering-Brown et al., 2006). I10 + 19 C $>\mathrm{G}$ was found in two cases (Stanford et al., 2003; Rohrer et al., 2009) and I9 + 33 G > A in one case (Rizzu et al., 1999) of FTLD; however, they have not been definitely characterized. I10 + 25 $\mathrm{C}>\mathrm{T}$ was detected both in affected and control subjects (Roks et al., 1999).

$\mathrm{I} 11+34 \mathrm{~A}>\mathrm{G}$ was reported to increase risk factor for $\mathrm{AD}$ when associated with ApoE 4 allele (Bullido et al., 2000).

\section{Gross Deletions or Duplications}

The only gross deletion involving a part of MAPT and giving rise to a FTLD phenotype was reported by Rovelet-Lecrux et al. (2009). The deletion spanned exons 6-9 and produced a truncated tau devoid of its first MBD. This tau showed pathological features such as a decreased binding to MT and the ability to sequester other MAPs, both impairing MT dynamics.

All the other deletions so far described are in fact deletions spanning large chromosome regions including MAPT and adjacent genes, that caused the so-called microdeletion syndromes, mostly characterized by mental retardation, developmental delay and dysmorphisms (Koolen et al., 2006; Sharp et al., 2006; Varela et al., 2006; Dubourg et al., 2011; Asadollahi et al., 2014).
In these cases the contributions of the single genes, such as MAPT, to the syndrome are not clearly understood.

Duplication cases are more interesting (Figure 3C). In the first case, following a screening of FTLD patients, a duplication was found, spanning four genes, including MAPT (Rovelet-Lecrux et al., 2010). In the second case, following a screening of familial $\mathrm{AD}$ cases, a duplication of the solely MAPT was discovered (Hooli et al., 2014). Unfortunately, neuropathological examination was not available in either cases; however the phenotype of dementia (FTLD or AD) seems to indicate a detrimental role of tau overexpression, accordingly to data from animal models (Spittaels et al., 1999; Andorfer et al., 2003). More recently, a very young case carrying a triplication of MAPT gene together with other genes was described to have moderate intellectual disability (Gregor et al., 2012).

These rearrangements are thought to be fostered by the genomic structure itself of this region containing the low-copy repeats and the inversion polymorphism (Cruts et al., 2005, 2012; Sharp et al., 2006).

\section{Unusual Pathogenetic Mechanisms Underlying Tau Mutations}

In addition to the role of MAP, other functions are ascribed to tau, which is presently considered a multifunctional protein (Morris et al., 2011) and a number of tau binding partners have been reported, including proteins, nucleic acids and organelles (Mandelkow and Mandelkow, 2012). Here, we only describe the functions that have been demonstrated to be compromised by a tau mutation. Mutations altering these various functions may sustain pathogenetic mechanisms different from the usual ones.

\section{Tau can Regulate Axonal Transport}

Tau can affect the binding of both dynein and kinesin motor proteins to MT, based on the distribution of tau along MT and the sensitivity of motor proteins to presence of tau (Dixit et al., 2008).

It has been demonstrated that the $\mathrm{N}$-terminal projection domain of tau binds to the p150 subunit of the dynactin complex, which has an essential role in axonal transport, and the attachment of the dynactin to MTs is enhanced by tau (Magnani et al., 2007). R5L and R5H mutations, found in patients with FTLD, affected in vitro tau binding to dynactin (Figure 4A). These findings suggest an involvement of tau in axonal transport and imply a subsequent pathogenetic role of tau mutations.

In an in vitro system, tau isoforms carrying P301L, $\Delta \mathrm{N} 296$, and R406W mutations were found to cause a slower kinesin translocation along MT with respect to wt tau (Yu et al., 2014; Figure 4A). As P301L and $\Delta$ N296 are localized in the $\mathrm{MBD}$, it was hypothesized that MT assembled and stabilized by mutant tau are structurally and functionally distinct from MT assembled by wt tau, leading to the slowing of kinesin velocities. R406W maps outside the $\mathrm{MBD}$, in the C-terminal region of tau; however, there are evidences that this region 


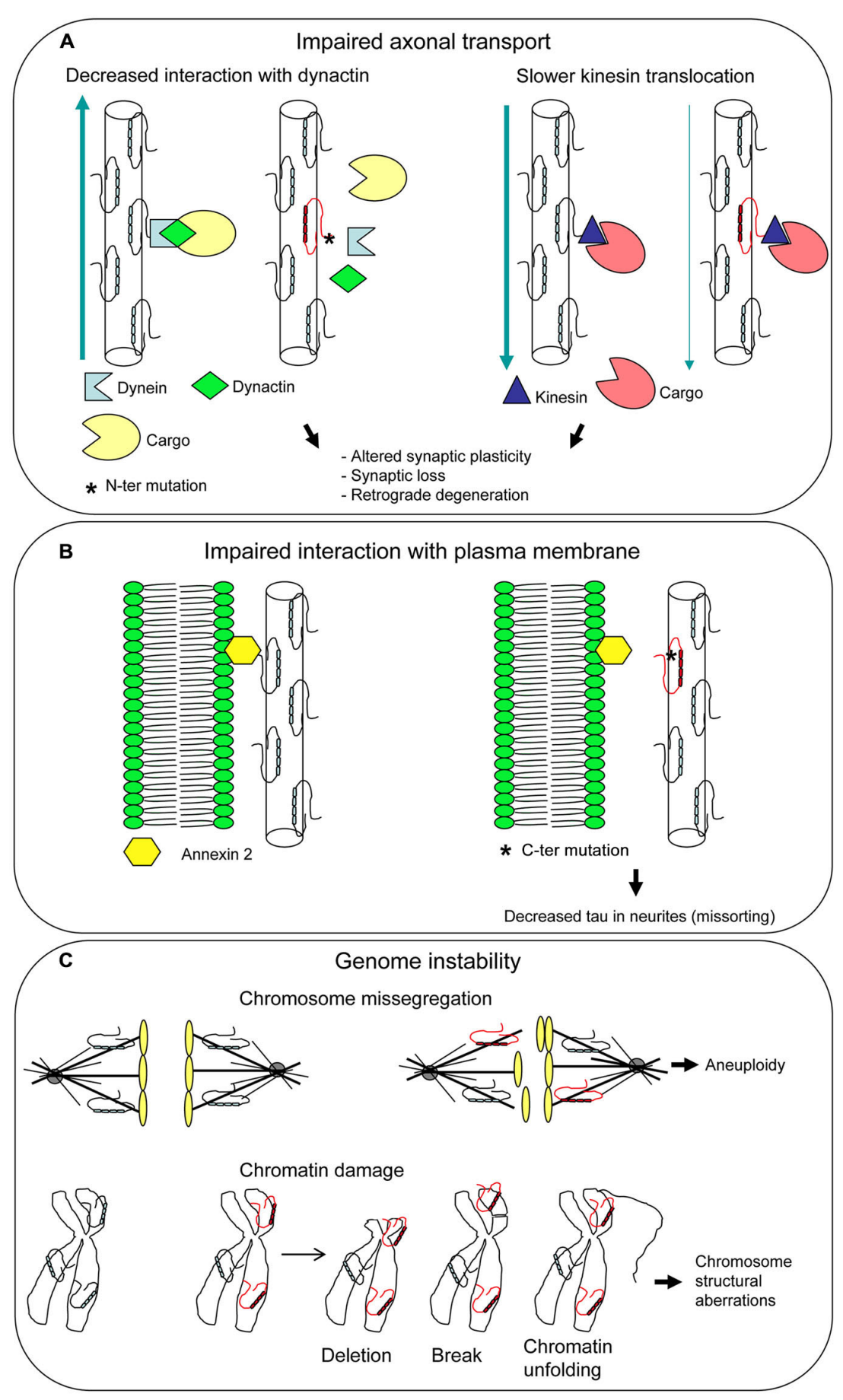

FIGURE 4 | Unusual pathogenetic mechanisms underlying tau mutations. Additional functions have been attributed to tau besides its role as a microtubule-associated protein (MAP). Mutations can affect all tau functions, disclosing new pathogenetic mechanisms. Impaired axonal transport (A) and interaction with plasma membarne (B) can lead to neuronal dysfunction and death. Mutated tau dysfunction as a mitotic spindle MAP may give rise to aneuploidy, while dysfunction as a chaperon protein protecting DNA may result in chromosome aberrations, both different aspects of genome instability (C).

influences the MT binding activity of tau (Jeganathan et al., 2006; Mukrasch et al., 2009). These findings provide support to the notion that tau-mediated aberrant modulation of kinesin translocation may lead to neuronal cell death and dementia.

\section{Tau Interacts with Plasma Membrane}

Binding of tau N-terminal projection domain to neuronal plasma membrane had been demonstrated years ago (Brandt et al., 1995). Recent work showed that R406W mutation abolishes taumembrane binding (Figure 4B), leading to a decreased presence 
of tau at the tip of neuritis ("loss of function" mechanism; Gauthier-Kemper et al., 2011). Tau-membrane interaction seems to support neurite extension, presumably by bridging the growing MTs to the membrane in the growth cone. This bridging appears to be mediated by annexin A2, an interaction partner of tau. Thus, R406W mutation would compromise tau-annexin A2 interaction, although an influence on tau $\mathrm{N}$-terminal domain cannot be ruled out (Gauthier-Kemper et al., 2011).

Missorting of tau from neurites to somatodendritic compartment is a pathological condition that characterizes neurodegenerative diseases (Zempel and Mandelkow, 2014). R406W mutation thus appears to contribute to this pathological aspect.

\section{Tau has Nuclear Functions and is Involved in Genome Stability}

Tau is localized not only in cytoskeleton, centrosome, and mitotic spindle MT but also in the nucleus (Sjöberg et al., 2006; Rossi et al., 2008a) and has the ability to bind to DNA and protect it from damage in a chaperon-like manner (Hua and He, 2003; Wei et al., 2008). In neuronal cultures, tau can translocate from cytoplasm to nucleus during heath shock, to prevent damage to DNA (Sultan et al., 2011) and a major role for tau in neuronal DNA and RNA protection in vivo under physiological and hyperthermic conditions was observed (Violet et al., 2014). In absence of tau, tau knock-out mice exhibited DNA damages such as chromosome missegregation and aneuploidy (Granic et al., 2010).

Tau can be involved in control of chromosome stability based on two different roles (Figure 4C). First, the well-known function as a MAP that regulates spindle MT dynamics. The dysfunction of a MAP can lead to genomic instability (Lengauer et al., 1998) and in fact a mutated tau was demonstrated to produce an unstable and overly dynamic spindle (Alonso et al., 2004; Bunker et al., 2006), which can cause chromosome missegregation and aneuploidy. Second, the interaction of tau with chromatin within the nucleus, that contributes to DNA stabilization and repair. A mutated dysfunctional tau may fail to protect DNA and enhance its damage. In both cases a "loss of function" mechanism can be envisaged.

According to these findings and hypotheses, we found that tau mutations are associated with genome and chromosome instability in peripheral cells of patients affected by FTLD. Cytogenetic analysis of peripheral blood lymphocytes and skin fibroblasts from patients carrying P301L, $\Delta$ N296, I10 + 3 G > A; I10 + 16 C > T, G335S, V363I, P364S, G366R, G389R and $\mathrm{D} 418 \mathrm{~N}$ revealed the presence of several chromosome aberrations such as gaps, breaks, deletions, translocations, aneuploidies, and chromatin anomalies (Rossi et al., 2013). We observed different kinds of aberrations among patients and also between lymphocytes and fibroblasts of the same patient. Thus, mutated tau can be regarded as a predisposing factor to chromosome instability, which appears to be stochastic and involving the whole genome. By in depth analysis of DNA copy number variations through molecular karyotyping, we detected a higher tendency to non-allelic homologous recombination in cells carrying a tau mutation than in cells with wt tau; this suggests a role of mutated tau in this abnormal recombination activity, probably due to its dysfunction as chromatin-associated protein ("gain of function"?; Rossi et al., 2013).

Searching for a confirmation of these results in animal models of genetic tauopathies, we demonstrated that mice expressing P301L and P301S tau mutations have higher aneuploidy levels in their lymphocytes than wt mice (Rossi et al., 2014b). Of course, the cytogenetic study should be extended to CNS, to reveal the presence of chromosome aberrations and to investigate their involvement in neurodegeneration. We hope this investigation will be performed in the future.

\section{Clinical Features and Diagnostic Implications}

Clinical phenotypes of genetic tauopathies are the same as sporadic tauopathies, that is bvFTD, SD, PNFA, PSP and CBS: in fact, tau mutations lead to heterogeneous phenotypes. A high clinical variability is also found both among and within families carrying the same mutation. P301S mutation gave rise to bvFTD in a father and CBD in his son (Bugiani et al., 1999); G389R mutation presented both as bvFTD or CBS (Rossi et al., 2008b); V363I led to bvFTD, SD, PNFA, as well as an atypical phenotype such as posterior cortical atrophy, in some unrelated cases (Rossi et al., 2014a). Thus, to establish a genotype-phenotype correlation within tauopathies is not possible. Moreover, due to clinical overlap between tauopathies and other diseases belonging to FTLD group, which is characterized by genetic heterogeneity, such a correlation is very difficult also in the whole clinical spectrum of FTDL.

When a new tau mutation is found and segregation analysis is not feasible and neuropathological study is not available, a hint about its pathogenicity may come from its position within the protein and comparison to similar previously characterized mutations; however, if possible, an in vitro structural and biochemical characterization should be performed to give better indications (Rossi et al., 2012). This would allow to provide affected families with a genetic counseling in which mutations can be attributed at least a likely benign or pathological nature.

A karyotype study on peripheral blood cells may suggest genomic instability; however, as the extent of this phenomenon in CNS in so far unknown, it has not a diagnostic nor prognostic value. We think that the pathological aspect of tau mutations involving DNA damage and chromosome instability should be further investigated for its implication not only in neurodegeneration but also in different diseases associated with genome instability, such as cancer.

\section{Conclusions}

Tau mutations usually alter the primary physiological function of tau as a MAP, that is to promote MT polymerization: in fact, most of missense mutations decrease this ability. This can destabilize the cytoskeleton and its functions in neurons. Mutated tau isoforms show often an increased tendency to self-aggregate into fibrillar deposits and this happens also in the case of mutations causing an imbalance between $3 \mathrm{R}$ and $4 \mathrm{R}$ tau isoforms. A 
mass of insoluble, hyperphosphorylated tau thus accumulates within neurons. Cytoskeleton disruption and fibrillar burden are the resulting damages to neuronal cells, leading finally to death.

MAP function of tau can be affected in an opposite way by a small group of mutations that increase the ability of tau to promote MT polymerization. The deriving overstabilization of MT can be detrimental to neuronal function such as axonal transport and synaptic plasticity.

Although fibrillar deposits are usually considered the tau harmful species to neurons, oligomeric tau aggregates have also toxic potential and some rare mutations leading to oligomer formation can explain their pathological effect in this way.

Tau is now more properly considered a multifunctional protein and mutations affecting some roles different from MAP function are emerging: in fact, some mutations were shown to alter dynein and/or kinesin motor proteins activity on MT, being able to slow the axonal flux.

Tau appears also to be involved in genome stability, due to its functions as a MAP and nuclear chromatin-associated protein. Several mutations have in fact been demonstrated to be associated with chromosome structural and numerical aberrations.

Very interestingly, some mutations were investigated for and attributed different pathological features. For example, P301L is a well-known mutation reducing MT polymerization and displaying a great self-aggregation ability; furthermore, it reduced kinesin translocation along MT and was associated

\section{References}

Alonso, A. C., Mederlyova, A., Novak, M., Grundke-Iqbal, I., and Iqbal, K. (2004). Promotion of hyperphosphorylation by frontotemporal dementia tau mutations. J. Biol. Chem. 279, 34873-34881. doi: 10.1074/jbc.m405131200

Alonso, A. D., Di Clerico, J., Li, B., Corbo, C. P., Alaniz, M. E., Grundke-Iqbal, I., et al. (2010). Phosphorylation of tau at Thr212, Thr231 and Ser262 combined causes neurodegeneration. J. Biol. Chem. 285, 30851-30860. doi: 10.1074/jbc. m110.110957

Alzheimer, A. (1907). Über eine eigenartige Erkrankung der Hirnrinde. Allg. Z. Psychiat. 64, 146-148.

Alzheimer, A. (1911). Über eigenartige Krankheitsfälle des späteren Alters. Z. Ges. Neurol. Psychiat. 4, 356-385. doi: 10.1007/bf02866241

Andorfer, C., Kress, Y., Espinoza, M., de Silva, R., Tucker, K. L., Barde, Y. A., et al. (2003). Hyperphosphorylation and aggregation of tau in mice expressing normal human tau isoforms. J. Neurochem. 86, 582-590. doi: 10.1046/j.14714159.2003.01879.x

Anfossi, M., Vuono, R., Maletta, R., Virdee, K., Mirabelli, M., Colao, R., et al. (2011). Compound heterozygosity of 2 novel MAPT mutations in frontotemporal dementia. Neurobiol. Aging 32, 757.e1-757.e11. doi: 10.1016/j. neurobiolaging.2010.12.013

Asadollahi, R., Oneda, B., Joset, P., Azzarello-Burri, S., Bartholdi, D., Steindl, K., et al. (2014). The clinical significance of small copy number variants in neurodevelopmental disorders. J. Med. Genet. 51, 677-688. doi: 10. 1136/jmedgenet-2014-102588

Baker, M., Litvan, I., Houlden, H., Adamson, J., Dickson, D., Perez-Tur, J., et al. (1999). Association of an extended haplotype in the tau gene with progressive supranuclear palsy. Hum. Mol. Genet. 8, 711-715. doi: 10.1093/hmg/8.4.711

Barghorn, S., Zheng-Fischhöfer, Q., Ackmann, M., Biernat, J., von Bergen, M., Mandelkow, E. M., et al. (2000). Structure, microtubule interactions and paired helical filament aggregation by tau mutants of frontotemporal dementias. Biochemistry 39, 11714-11721. doi: 10.1021/bi000850r with several chromosome aberrations in human and animal cells. Thus, because of the recognized role of tau as a multifunctional protein, a mutation should in turn be considered as potentially having pleiotropic effects disclosing the complex neurodegenerative processes leading to cell death and eventually dementia.

Depending upon the function of tau that is affected and the way it is affected, a tau mutation can cause either a "gain of function" or a "loss of function" condition. A "gain of function" is present in association with fibrillar and/or oligomeric aggregates and in case of MT overstabilization. A "loss of function" possibly occurs in cases of MT destabilization, loss of tau-partner protein interaction, DNA damage and chromosome instability. Complex pathological mechanisms must then be considered when investigating tau-driven neurodegeneration.

Accordingly, therapeutic strategies for tauopathies should take into account all the possibly compromised functions of tau to be successful, targeting tau phosphorylation features and aggregation tendency, oligomer toxicity, MT destabilization/overstabilization (for review, see Boxer et al., 2013; Spillantini and Goedert, 2013; Gerson et al., 2014), as well as DNA and chromosome damage (Rossi et al., 2013, 2014b; Violet et al., 2014), a pathological aspect until now neglected.

\section{Acknowledgments}

This study was supported by research grant from Ricerca Corrente, Italian Ministry of Health.

Berger, Z., Roder, H., Hanna, A., Carlson, A., Rangachari, V., Yue, M., et al. (2007) Accumulation of pathological tau species and memory loss in a conditional model of tauopathy. J. Neurosci. 27, 3650-3662. doi: 10.1523/jneurosci.058707.2007

Boxer, A. L., Gold, M., Huey, E., Gao, F. B., Burton, E. A., Chow, T., et al. (2013). Frontotemporal degeneration, the next therapeutic frontier: molecules and animal models for frontotemporal degeneration drug development. Alzheimers Dement. 9, 176-188. doi: 10.1016/j.jalz.2012.03.002

Brandt, R., Léger, J., and Lee, G. (1995). Interaction of tau with the neural plasma membrane mediated by tau's amino-terminal projection domain. J. Cell Biol. 131, 1327-1340. doi: 10.1083/jcb.131. 5.1327

Buée, L., Bussiére, T., Buée-Scherrer, V., Delacourte, A., and Hof, P. R. (2000). Tau protein isoforms, phosphorylation and role in neurodegenerative disorders. Brain Res. Brain Res. Rev. 33, 95-130. doi: 10.1016/s0165-0173(00) 00019-9

Bugiani, O., Murrell, J. R., Giaccone, G., Hasegawa, M., Ghigo, G., Tabaton, M., et al. (1999). Frontotemporal dementia and corticobasal degeneration in a family with a P301S mutation in tau. J. Neuropathol. Exp. Neurol. 58, 667-677. doi: 10.1097/00005072-199906000-00011

Bullido, M. J., Aldudo, J., Frank, A., Coria, F., Avila, J., and Valdivieso, F. (2000). A polymorphism in the tau gene associated with risk for Alzheimer's disease. Neurosci. Lett. 278, 49-52. doi: 10.1016/s0304-3940(99) 00893-9

Bunker, J. M., Kamath, K., Wilson, L., Jordan, M. A., and Feinstein, S. C. (2006). FTDP-17 mutations compromise the ability of tau to regulate microtubule dynamics in cells. J. Biol. Chem. 281, 11856-11863. doi: 10. 1074/jbc.m509420200

Chang, E., Kim, S., Yin, H., Nagaraja, H. N., and Kure, J. (2008). Pathogenic missense MAPT mutations differentially modulate tau aggregation propensity at nucleation and extension steps. J. Neurochem. 107, 1113-1123. doi: 10.1111/j. 1471-4159.2008.05692.x 
Conrad, C., Andreadis, A., Trojanowski, J. Q., Dickson, D. W., Kang, D., Chen, X., et al. (1997). Genetic evidence for the involvement of tau in progressive supranuclear palsy. Ann. Neurol. 41, 277-281. doi: 10.1002/ana.410410222

Coppola, G., Chinnathambi, S., Lee, J. J., Dombroski, B. A., Baker, M. C., SotoOrtolaza, A. I., et al. (2012). Evidence for a role of the rare p.A152T variant in MAPT in increasing the risk for FTD-spectrum and Alzheimer's diseases. Hum. Mol. Genet. 21, 3500-3512. doi: 10.1093/hmg/dds161

Cruchaga, C., Haller, G., Chakraverty, S., Mayo, K., Vallania, F. L., Mitra, R. D., et al. (2012). Rare variants in APP, PSEN1 and PSEN2 increase risk for $\mathrm{AD}$ in late-onset Alzheimer's disease families. PLoS One 7:e31039. doi: 10. 1371/journal.pone.0031039

Cruchaga, C., Vidal-Taboada, J. M., Ezquerra, M., Lorenzo, E., Martinez-Lage, P., Blazquez, M., et al. (2009). 5'-Upstream variants of CRHR1 and MAPT genes associated with age at onset in progressive supranuclear palsy and cortical basal degeneration. Neurobiol. Dis. 33, 164-170. doi: 10.1016/j.nbd.2008. 09.027

Cruts, M., Rademakers, R., Gijselinck, I., van der Zee, J., Dermaut, B., de Pooter, T., et al. (2005). Genomic architecture of human 17q21 linked to frontotemporal dementia uncovers a highly homologous family of low-copy repeats in the tau region. Hum. Mol. Genet. 14, 1753-1762. doi: 10.1093/hmg/ddi182

Cruts, M., Theuns, J., and Van Broeckhoven, C. (2012). Locus-specific mutation databases for neurodegenerative brain diseases. Hum. Mutat. 33, 1340-1344. doi: 10.1002/humu.22117

de Silva, R., Weiler, M., Morris, H. R., Martin, E. R., Wood, N. W., and Lees, A. J. (2001). Strong association of a novel Tau promoter haplotype in progressive supranuclear palsy. Neurosci. Lett. 311, 145-148. doi: 10. 1016/s0304-3940(01)02109-7

Di Fonzo, A., Ronchi, D., Gallia, F., Cribiù, F. M., Trezzi, I., Vetro, A., et al. (2014). Lower motor neuron disease with respiratory failure caused by a novel MAPT mutation. Neurology 82, 1990-1998. doi: 10.1212/wnl.0000000000000476

Dickson, D. W., Kouri, N., Murray, M. E., and Josephs, K. A. (2011). Neuropathology of frontotemporal lobar degeneration-tau (FTLD-tau). J. Mol. Neurosci. 45, 384-389. doi: 10.1007/s12031-011-9589-0

Dixit, R., Ross, J. L., Goldman, Y. E., and Holzbaur, E. L. (2008). Differential regulation of dynein and kinesin motor proteins by tau. Science 319, 1086-1089. doi: 10.1126/science.1152993

D’Souza, I., Poorkaj, P., Hong, M., Nochlin, D., Lee, V. M., Bird, T. D., et al. (1999). Missense and silent tau gene mutations cause frontotemporal dementia with parkinsonism-chromosome 17 type, by affecting multiple alternative RNA splicing regulatory elements. Proc. Natl. Acad. Sci. US A 96, 5598-5603. doi: 10. 1073/pnas.96.10.5598

D'Souza, I., and Schellenberg, G. D. (2002). Tau Exon 10 expression involves a bipartite intron 10 regulatory sequence and weak $5^{\prime}$ and $3^{\prime}$ splice sites. J. Biol. Chem. 277, 26587-26599. doi: 10.1074/jbc.m203794200

Dubourg, C., Sanlaville, D., Doco-Fenzy, M., Le Caignec, C., Missirian, C., Jaillard, S., et al. (2011). Clinical and molecular characterization of 17q21.31 microdeletion syndrome in 14 French patients with mental retardation. Eur. J. Med. Genet. 54, 144-151. doi: 10.1016/j.ejmg.2010.11.003

Gauthier-Kemper, A., Weissmann, C., Golovyashkina, N., Sebö-Lemke, Z., Drewes, G., Gerke, V., et al. (2011). The frontotemporal dementia mutation R406W blocks tau's interaction with the membrane in an annexin A2dependent manner. J. Cell. Biol. 192, 647-661. doi: 10.1083/jcb.201007161

Gerson, J. E., Castillo-Carranza, D. L., and Kayed, R. (2014). Advances in therapeutics for neurodegenerative tauopathies: moving toward the specific targeting of the most toxic tau species. ACS Chem. Neurosci. 5, 752-769. doi: 10. $1021 / \mathrm{cn} 500143 \mathrm{n}$

Gerson, J. E., and Kayed, R. (2013). Formation and propagation of tau oligomeric seeds. Front. Neurol. 4:93. doi: 10.3389/fneur.2013.00093

Goedert, M., and Jakes, R. (1990). Expression of separate isoforms of human tau protein: correlation with the tau pattern in brain and effects on tubulin polymerization. EMBO J. 9, 4225-4230.

Goedert, M., Spillantini, M. G., Cairns, N. J., and Crowther, R. A. (1992). Tau proteins of Alzheimer paired helical filaments: abnormal phosphorylation of all six brain isoforms. Neuron 8, 159-168. doi: 10.1016/0896-6273(92)90117-v

Goedert, M., Spillantini, M. G., Potier, M. C., Ulrich, J., and Crowther, R. A. (1989a). Cloning and sequencing of the cDNA encoding an isoform of microtubule-associated protein tau containing four tandem repeats: differential expression of tau protein mRNAs in human brain. EMBO J. 8, 393-399.
Goedert, M., Spillantini, M. G., Jakes, R., Rutherford, D., and Crowther, R. A. (1989b). Multiple isoforms of human microtubule-associated protein tau: sequences and localization in neurofibrillary tangles of Alzheimer's disease. Neuron 3, 519-526. doi: 10.1016/0896-6273(89)90210-9

Goedert, M., Wischik, C. M., Crowther, R. A., Walker, J. E., and Klug, A. (1988). Cloning and sequencing of the cDNA encoding a core protein of the paired helical filament of Alzheimer disease. Proc. Natl. Acad. Sci. U S A 85, 4051-4055. doi: 10.1073/pnas.85.11.4051

Gómez-Ramos, A., Díaz-Hernández, M., Rubio, A., Miras-Portugal, M. T., and Avila, J. (2008). Extracellular tau promotes intracellular calcium increase through M1 and M3 muscarinic receptors in neuronal cells. Mol. Cell. Neurosci. 37, 673-681. doi: 10.1016/j.mcn.2007.12.010

Goode, B. L., Chau, M., Denis, P. E., and Feinstein, S. C. (2000). Structural and functional differences between 3-repeat and 4-repeat tau isoforms. Implications for normal tau function and the onset of neurodegenetative disease. J. Biol. Chem. 275, 38182-38189. doi: 10.1074/jbc.m007489200

Goode, B. L., and Feinstein, S. C. (1994). Identification of a novel microtubule binding and assembly domain in the developmentally regulated inter-repeat region of tau. J. Cell Biol. 124, 769-782. doi: 10.1083/jcb.124.5.769

Götz, J., Deters, N., Doldissen, A., Bokhari, L., Ke, Y., Wiesner, A., et al. (2007). A decade of tau transgenic animal models and beyond. Brain Pathol. 17, 91-103. doi: 10.1111/j.1750-3639.2007.00051.x

Granic, A., Padmanabhan, J., Norden, M., and Potter, H. (2010). Alzheimer Abeta peptide induces chromosome missegregation and aneuploidy, including trisomy 21: Requirement for tau and APP. Mol. Biol. Cell 21, 511-520. doi: 10. 1091/mbc.e09-10-0850

Gregor, A., Krumbiegel, M., Kraus, C., Reis, A., and Zweier, C. (2012). De novo triplication of the MAPT gene from the recurrent $17 \mathrm{q} 21.31$ microdeletion region in a patient with moderate intellectual disability and various minor anomalies. Am. J. Med. Genet 158A, 1765-1770. doi: 10. 1002/ajmg.a.35427

Grover, A., DeTure, M., Yen, S. H., and Hutton, M. (2002). Effects on splicing and protein function of three mutations in codon N296 of tau in vitro. Neurosci. Lett. 323, 33-36. doi: 10.1016/s0304-3940(02)00124-6

Guerreiro, R. J., Washecka, N., Hardy, J., and Singleton, A. (2010). A thorough assessment of benign genetic variability in GRN and MAPT. Hum. Mutat. 31, E1126-E1140. doi: 10.1002/humu.21152

Gustke, N., Trinczek, B., Biernat, J., Mandelkow, E. M., and Mandelkow, E. (1994). Domains of tau protein and interactions with microtubules. Biochemistry 33, 9511-9522. doi: 10.1021/bi00198a017

Hasegawa, M., Smith, M. J., and Goedert, M. (1998). Tau proteins with FTDP-17 mutations have a reduced ability to promote microtubule assembly. FEBS Lett. 437, 207-210. doi: 10.1016/s0014-5793(98)01217-4

Hasegawa, M., Smith, M. J., Iijima, M., Tabira, T., and Goedert, M. (1999). FTDP17 mutations $\mathrm{N} 279 \mathrm{~K}$ and $\mathrm{S} 305 \mathrm{~N}$ in tau produce increased splicing of exon 10 FEBS Lett. 443, 93-96. doi: 10.1016/s0014-5793(98)01696-2

Hayashi, S., Toyoshima, Y., Hasegawa, M., Umeda, Y., Wakabayashi, K., Tokiguchi, S., et al. (2002). Late-onset frontotemporal dementia with a novel exon 1 (Arg5His) tau gene mutation. Ann. Neurol. 51, 525-530. doi: 10 1002/ana.10163

Hong, M., Zhukareva, V., Vogelsberg-Ragaglia, V., Wszolek, Z., Reed, L., Miller, B. I., et al. (1998). Mutation-specific functional impairments in distinct tau isoforms of hereditary FTDP-17. Science 282, 1914-1917. doi: 10.1126/science. 282.5395.1914

Hooli, B. V., Kovacs-Vajna, Z. M., Mullin, K., Blumenthal, M. A., Mattheisen, M., Zhang, C., et al. (2014). Rare autosomal copy number variations in early-onset familial Alzheimer's disease. Mol. Psychiatry 19, 676-681. doi: 10.1038/mp. 2013.77

Hua, Q., and He, R. Q. (2003). Tau could protect DNA double helix structure. Biochim. Biophys. Acta 1645, 205-211. doi: 10.1016/s1570-9639(02) 00538-1

Hutton, M., Lendon, C. L., Rizzu, P., Baker, M., Froelich, S., Houlden, H., et al. (1998). Association of missense and $5^{\prime}$-splice-site mutations in tau with the inherited dementia FTDP-17. Nature 393, 702-705. doi: 10.1038/31508

Iliev, A. I., Ganesan, S., Bunt, G., and Wouters, F. S. (2006). Removal of patternbreaking sequences in microtubule binding repeats produces instantaneous tau aggregation and toxicity. J. Biol. Chem. 281, 37195-37204. doi: 10.1074/jbc. m604863200 
Ingelson, M., Vanmechelen, E., and Lannfelt, L. (1996). Microtubule-associated protein tau in human fibroblasts with the Swedish Alzheimer mutation. Neurosci. Lett. 220, 9-12. doi: 10.1016/s0304-3940(96)13218-3

Iqbal, K., Liu, F., Gong, C. X., Alonso, A. C., and Grundke-Iqbal, I. (2009). Mechanisms of tau-induced neurodegeneration. Acta Neuropathol. 118, 53-69. doi: 10.1007/s00401-009-0486-3

Iyer, A., Lapointe, N. E., Zielke, K., Berdynski, M., Guzman, E., Barczak, A., et al. (2013). A novel MAPT mutation, G55R, in a frontotemporal dementia patient leads to altered Tau function. PLoS One 8:e76409. doi: 10.1371/journal.pone. 0076409

Jeganathan, S., von Bergen, M., Brutlach, H., Steinhoff, H. J., and Mandelkow, E. (2006). Global hairpin folding of tau in solution. Biochemistry 45, 2283-2293. doi: 10.1021/bi0521543

Jin, S. C., Pastor, P., Cooper, B., Cervantes, S., Benitez, B. A., Razquin, C., et al. (2012). Pooled-DNA sequencing identifies novel causative variants in PSEN1, GRN and MAPT in a clinical early-onset and familial Alzheimer's disease Ibero-American cohort. Alzheimers Res. Ther. 4:34. doi: 10.1186/ alzrt137

Kara, E., Ling, H., Pittman, A. M., Shaw, K., de Silva, R., Simone, R., et al. (2012). The MAPT p.A152T variant is a risk factor associated with tauopathies with atypical clinical and neuropathological features. Neurobiol. Aging 33, 2231.e7-2231.e14. doi: 10.1016/j.neurobiolaging.2012.04.006

Kim, E. J., Kwon, J. C., Park, K. H., Park, K. W., Lee, J. H., Choi, S. H., et al. (2014). Clinical and genetic analysis of MAPT, GRN and C9orf72 genes in Korean patients with frontotemporal dementia. Neurobiol. Aging 35, 1213.e13-1213.e17. doi: 10.1016/j.neurobiolaging.2013.11.033

King, A., Al-Sarraj, S., Troakes, C., Smith, B. N., Maekawa, S., Iovino, M., et al. (2013). Mixed tau, TDP-43 and p62 pathology in FTLD associated with a C9ORF72 repeat expansion and p.Ala239Thr MAPT (tau) variant. Acta Neuropathol. 125, 303-310. doi: 10.1007/s00401-012-1050-0

Koolen, D. A., Vissers, L. E., Pfundt, R., de Leeuw, N., Knight, S. J., Regan, R., et al. (2006). A new chromosome 17q21.31 microdeletion syndrome associated with a common inversion polymorphism. Nat. Genet. 38, 999-1001. doi: 10. $1038 /$ ng 1853

Kouri, N., Carlomagno, Y., Baker, M., Liesinger, A. M., Caselli, R. J., Wszolek, Z. K., et al. (2014). Novel mutation in MAPT exon 13 (p.N410H) causes corticobasal degeneration. Acta Neuropathol. 127, 271-282. doi: 10. 1007/s00401-013-1193-7

Kovacs, G. G., Pittman, A., Revesz, T., Luk, C., Lees, A., Kiss, E., et al. (2008). MAPT S305I mutation: implications for argyrophilic grain disease. Acta Neuropathol. 116, 103-118. doi: 10.1007/s00401-007-0322-6

Kovacs, G. G., Wöhrer, A., Ströbel, T., Botond, G., Attems, J., and Budka, H. (2011). Unclassifiable tauopathy associated with an A152T variation in MAPT exon 7. Clin. Neuropathol. 30, 3-10. doi: 10.5414/npp30003

Larini, L., Gessel, M. M., LaPointe, N. E., Do, T. D., Bowers, M. T., Feinstein, S. C., et al. (2013). Initiation of assembly of tau (273-284) and its $\Delta K 280$ mutant: an experimental and computational study. Phys. Chem. Chem. Phys. 15, 8916-8928. doi: 10.1039/c3cp00063j

Lasagna-Reeves, C. A., Castillo-Carranza, D. L., Guerrero-Muoz, M. J., Jackson, G. R., and Kayed, R. (2010). Preparation and characterization of neurotoxic tau oligomers. Biochemistry 49, 10039-10041. doi: 10.1021/bi1 016233

Lengauer, C., Kinzler, K. W., and Vogelstein, B. (1998). Genetic instabilities in human cancers. Nature 396, 643-649. doi: 10.1038/25292

Levy, S. F., Leboeuf, A. C., Massie, M. R., Jordan, M. A., Wilson, L., and Feinstein, S. C. (2005). Three- and four-repeat tau regulate the dynamic instability of two distinct microtubule subpopulations in qualitatively different manners. Implications for neurodegeneration. J. Biol. Chem. 280, 13520-13528. doi: 10. 1074/jbc.m413490200

Ling, H., Kara, E., Bandopadhyay, R., Hardy, J., Holton, J., Xiromerisiou, G., et al. (2013). TDP-43 pathology in a patient carrying G2019S LRRK2 mutation and a novel p.Q124E MAPT. Neurobiol. Aging 34, 2889.e5-2889.e9. doi: 10.1016/j. neurobiolaging.2013.04.011

Lippa, C. F., Zhukareva, V., Kawarai, T., Uryu, K., Shafiq, M., Nee, L. E., et al. (2000). Frontotemporal dementia with novel tau pathology and a Glu342Val tau mutation. Ann. Neurol. 48, 850-858. doi: 10.1002/15318249(200012)48:6<850::aid-ana5>3.3.co;2-m

Maeda, S., Sahara, N., Saito, Y., Murayama, S., Ikai, A., and Takashima, A. (2006). Increased levels of granular tau oligomers: an early sign of brain aging and
Alzheimer's disease. Neurosci. Res. 54, 197-201. doi: 10.1016/j.neures.2005. 11.009

Magnani, E., Fan, J., Gasparini, L., Golding, M., Williams, M., Schiavo, G., et al. (2007). Interaction of tau protein with the dynactin complex. EMBO J. 26, 4546-4554. doi: 10.1038/sj.emboj.7601878

Malkani, R., D’Souza, I., Gwinn-Hardy, K., Schellenberg, G. D., Hardy, J., and Momeni, P. A. (2006). MAPT mutation in a regulatory element upstream of exon 10 causes frontotemporal dementia. Neurobiol. Dis. 22, 401-403. doi: 10. 1016/j.nbd.2005.12.001

Mandelkow, E. M., and Mandelkow, E. (2012). Biochemistry and cell biology of tau protein in neurofibrillary degeneration. Cold Spring Harb. Perspect. Med. 2:a006247. doi: 10.1101/cshperspect.a006247

Meeus, B., Verstraeten, A., Crosiers, D., Engelborghs, S., Van den Broeck, M., Mattheijssens, M., et al. (2012). DLB and PDD: a role for mutations in dementia and Parkinson disease genes? Neurobiol. Aging 33, 629.e5-629.e18. doi: 10. 1016/j.neurobiolaging.2011.10.014

Momeni, P., Pittman, A., Lashley, T., Vandrovcova, J., Malzer, E., Luk, C., et al. (2009). Clinical and pathological features of an Alzheimer's disease patient with the MAPT Delta K280 mutation. Neurobiol. Aging 30, 388-393. doi: 10.1016/j. neurobiolaging.2007.07.013

Mori, K., Wenig, S. M., Arzberger, T., May, S., Rentzsch, K., Kremmer, E., et al. (2013). The C9orf72 GGGGCC repeat is translated into aggregating dipeptiderepeat proteins in FTLD/ALS. Science 339, 1335-1338. doi: 10.1126/science. 1232927

Morris, M., Maeda, S., Vossel, K., and Mucke, L. (2011). The many faces of tau. Neuron 70, 410-426. doi: 10.1016/j.neuron.2011.04.009

Mukrasch, M. D., Bibow, S., Korukottu, J., Jeganathan, S., Biernat, J., Griesinger, C., et al. (2009). Structural polymorphism of 441-residue tau at single residue resolution. PLoS Biol. 7:e34. doi: 10.1371/journal.pbio.1000034

Mukrasch, M. D., Biernat, J., von Bergen, M., Griesinger, C., Mandelkow, E., and Zweckstetter, M. (2005). Sites of tau important for aggregation populate beta-structure and bind to microtubules and polyanions. J. Biol. Chem. 280, 24978-24986. doi: 10.1074/jbc.m501565200

Murrell, J. R., Spillantini, M. G., Zolo, P., Guazzelli, M., Smith, M. J., Hasegawa, M., et al. (1999). Tau gene mutation G389R causes a tauopathy with abundant pick body-like inclusions and axonal deposits. J. Neuropathol. Exp. Neurol. 58, 1207-1226. doi: 10.1097/00005072-199912000-00002

Myers, A. J., Pittman, A. M., Zhao, A. S., Rohrer, K., Kaleem, M., Marlowe, L., et al. (2007). The MAPT H1c risk haplotype is associated with increased expression of tau and especially of 4 repeat containing transcripts. Neurobiol. Dis. 25, 561-570. doi: 10.1016/j.nbd.2006.10.018

Neumann, M., Schulz-Schaeffer, W., Crowther, R. A., Smith, M. J., Spillantini, M. G., Goedert, M., et al. (2001). Pick's disease associated with the novel Tau gene mutation K369I. Ann. Neurol. 50, 503-513. doi: 10.1002/ana.1223

Nicholl, D. J., Greenstone, M. A., Clarke, C. E., Rizzu, P., Crooks, D., Crowe, A., et al. (2003). An English kindred with a novel recessive tauopathy and respiratory failure. Ann. Neurol. 54, 682-686. doi: 10.1002/ana. 10747

Pickering-Brown, S. M., Baker, M., Gass, J., Boeve, B. F., Loy, C. T., Brooks, W. S., et al. (2006). Mutations in progranulin explain atypical phenotypes with variants in MAPT. Brain 129, 3124-3126. doi: 10.1093/brain/awl289

Pickering-Brown, S. M., Baker, M., Nonaka, T., Ikeda, K., Sharma, S., Mackenzie, J., et al. (2004). Frontotemporal dementia with Pick-type histology associated with Q336R mutation in the tau gene. Brain 127, 1415-1426. doi: 10. 1093/brain/awh147

Pickering-Brown, S. M., Richardson, A. M., Snowden, J. S., McDonagh, A. M., Burns, A., Braude, W., et al. (2002). Inherited frontotemporal dementia in nine British families associated with intronic mutations in the tau gene. Brain 125, 732-751. doi: 10.1093/brain/awf069

Pickering-Brown, S., Baker, M., Yen, S. H., Liu, W. K., Hasegawa, M., Cairns, N., et al. (2000). Pick's disease is associated with mutations in the tau gene. Ann. Neurol. 48, 859-867. doi: 10.1002/1531-8249(200012)48:6<859::aid-ana6>3.3. co;2-t

Pittman, A. M., Myers, A. J., Abou-Sleiman, P., Fung, H. C., Kaleem, M., Marlowe, L., et al. (2005). Linkage disequilibrium fine mapping and haplotype association analysis of the tau gene in progressive supranuclear palsy and corticobasal degeneration. J. Med. Genet. 42, 837-846. doi: 10.1136/jmg.2005.031377

Poorkaj, P., Muma, N. A., Zhukareva, V., Cochran, E. J., Shannon, K. M., Hurtig, H., et al. (2002). An R5L tau mutation in a subject with a progressive 
supranuclear palsy phenotype. Ann. Neurol. 52, 511-516. doi: 10.1002/ana. 10340

Rademakers, R., Neumann, M., and Mackenzie, I. R. (2012). Advances in understanding the molecular basis of frontotemporal dementia. Nat. Rev. Neurol. 8, 423-434. doi: 10.1038/nrneurol.2012.117

Rizzu, P., Van Swieten, J. C., Joosse, M., Hasegawa, M., Stevens, M., Tibben, A., et al. (1999). High prevalence of mutations in the microtubule-associated protein tau in a population study of frontotemporal dementia in the Netherlands. Am. J. Hum. Genet. 64, 414-421. doi: 10.1086/302256

Rohrer, J. D., and Warren, J. D. (2011). Phenotypic signatures of genetic frontotemporal dementia. Curr. Opin. Neurol. 24, 542-549. doi: 10.1097/wco. 0b013e32834cd442

Rohrer, J. D., Guerreiro, R., Vandrovcova, J., Uphill, J., Reiman, D., Beck, J., et al. (2009). The heritability and genetics of frontotemporal lobar degeneration. Neurology 73, 1451-1456. doi: 10.1212/WNL.0b013e3181bf997a

Roks, G., Dermaut, B., Heutink, P., Julliams, A., Backhovens, H., Van de Broeck, M., et al. (1999). Mutation screening of the tau gene in patients with early-onset Alzheimer's disease. Neurosci. Lett. 277, 137-139. doi: 10. 1016/s0304-3940(99)00861-7

Rossi, G., Bastone, A., Piccoli, E., Mazzoleni, G., Morbin, M., Uggetti, A., et al. (2012). New mutations in MAPT gene causing frontotemporal lobar degeneration: biochemical and structural characterization. Neurobiol. Aging 33, 834.e1-834.e6. doi: 10.1016/j.neurobiolaging.2011.08.008

Rossi, G., Bastone, A., Piccoli, E., Morbin, M., Mazzoleni, G., Fugnanesi, V., et al. (2014a). Different mutations at V363 MAPT codon are associated with atypical clinical phenotypes and show unusual structural and functional features. Neurobiol. Aging 35, 408-417. doi: 10.1016/j.neurobiolaging.2013. 08.004

Rossi, G., Conconi, D., Panzeri, E., Paoletta, L., Piccoli, E., Ferretti, M. G., et al. (2014b). Mutations in MAPT give rise to aneuploidy in animal models of tauopathy. Neurogenetics 15, 31-40. doi: 10.1007/s10048-013-0380-y

Rossi, G., Conconi, D., Panzeri, E., Redaelli, S., Piccoli, E., Paoletta, L., et al. (2013). Mutations in MAPT gene cause chromosome instability and introduce copy number variations widely in the genome. J. Alzheimers. Dis. 33, 969-982. doi: 10.3233/JAD-2012-121633

Rossi, G., Dalprà, L., Crosti, F., Lissoni, S., Sciacca, F. L., Catania, M., et al. (2008a). A new function of microtubule-associated protein tau: involvement in chromosome stability. Cell Cycle 7, 1788-1794. doi: 10.4161/cc.7.12.6012

Rossi, G., Marelli, C., Farina, L., Laurà, M., Maria Basile, A., Ciano, C., et al. (2008b). The G389R mutation in the MAPT gene presenting as sporadic corticobasal syndrome. Mov. Disord. 23, 892-895. doi: 10.1002/mds.21970

Rovelet-Lecrux, A., Hannequin, D., Guillin, O., Legallic, S., Jurici, S., Wallon, D., et al. (2010). Frontotemporal dementia phenotype associated with MAPT gene duplication. J. Alzheimers Dis. 21, 897-902. doi: 10.3233/JAD-2010-100441

Rovelet-Lecrux, A., Lecourtois, M., Thomas-Anterion, C., Le Ber, I., Brice, A., Frebourg, T., et al. (2009). Partial deletion of the MAPT gene: a novel mechanism of FTDP-17. Hum. Mutat. 30, E591-E602. doi: 10.1002/humu. 20979

Sharp, A. J., Hansen, S., Selzer, R. R., Cheng, Z., Regan, R., Hurst, J. A., et al. (2006). Discovery of previously unidentified genomic disorders from the duplication architecture of the human genome. Nat. Genet. 38, 1038-1042. doi: $10.1038 /$ ng 1862

Sjöberg, M. K., Shestakova, E., Mansuroglu, Z., Maccioni, R. B., and Bonnefoy, E. (2006). Tau protein binds to pericentromeric DNA: a putative role for nuclear tau in nucleolar organization. J. Cell Sci. 119, 2025-2034. doi: 10.1242/jcs.02907

Spillantini, M. G., and Goedert, M. (2000). Tau mutations in familial frontotemporal dementia. Brain 123, 857-859. doi: 10.1093/brain/123.5.857

Spillantini, M. G., and Goedert, M. (2013). Tau pathology and neurodegeneration. Lancet Neurol. 12, 609-622. doi: 10.1016/S1474-4422(13)70090-5

Spillantini, M. G., Murrell, J. R., Goedert, M., Farlow, M. R., Klug, A., and Ghetti, B. (1998). Mutation in the tau gene in familial multiple system tauopathy with presenile dementia. Proc. Natl. Acad. Sci. U S A 95, 7737-7741. doi: 10. 1073/pnas.95.13.7737

Spires-Jones, T. L., Stoothoff, W. H., de Calignon, A., Jones, P. B., and Hyman, B. T. (2009). Tau pathophysiology in neurodegeneration: a tangled issue. Trends Neurosci. 32, 150-159. doi: 10.1016/j.tins.2008.11.007

Spittaels, K., Van den Haute, C., Van Dorpe, J., Bruynseels, K., Vandezande, K., Laenen, I., et al. (1999). Prominent axonopathy in the brain and spinal cord of transgenic mice overexpressing four repeat human tau protein. Am. J. Pathol. 155, 2153-2165. doi: 10.1016/s0002-9440(10)65533-2

Spittaels, K., Van den Haute, C., Van Dorpe, J., Geerts, H., Mercken, M., Bruynseels, K., et al. (2000). Glycogen synthase kinase-3beta phosphorylates protein tau and rescues the axonopathy in the central nervous system of human four-repeat tau transgenic mice. J. Biol. Chem. 275, 41340-41349. doi: 10. 1074/jbc.m006219200

Stanford, P. M., Halliday, G. M., Brooks, W. S., Kwok, J. B., Storey, C. E., Creasey, H., et al. (2000). Progressive supranuclear palsy pathology caused by a novel silent mutation in exon 10 of the tau gene: expansion of the disease phenotype caused by tau gene mutations. Brain 123, 880-893. doi: 10.1093/brain/ 123.5.880

Stanford, P. M., Shepherd, C. E., Halliday, G. M., Brooks, W. S., Schofield, P. W., Brodaty, H., et al. (2003). Mutations in the tau gene that cause an increase in three repeat tau and frontotemporal dementia. Brain 126, 814-826. doi: 10. 1093/brain/awg090

Stefansson, H., Helgason, A., Thorleifsson, G., Steinthorsdottir, V., Masson, G., Barnard, J., et al. (2005). A common inversion under selection in Europeans. Nat. Genet. 37, 129-137. doi: 10.1038/ng1508

Stenson, P. D., Mort, M., Ball, E. V., Shaw, K., Phillips, A. D., and Cooper, D. N. (2014). The human gene mutation database: building a comprehensive mutation repository for clinical and molecular genetics, diagnostic testing and personalized genomic medicine. Hum. Genet. 133, 1-9. doi: 10.1007/s00439013-1358-4

Sultan, A., Nesslany, F., Violet, M., Bégard, S., Loyens, A., Talahari, S., et al. (2011). Nuclear tau, a key player in neuronal DNA protection. J. Biol. Chem. 286, 4566-4575. doi: 10.1074/jbc.m110.199976

Sun, W., and Jia, J. (2009). The +347 C promoter allele up-regulates MAPT expression and is associated with Alzheimer's disease among the Chinese Han. Neurosci. Lett. 450, 340-343. doi: 10.1016/j.neulet.2008. 11.067

Tacik, P., DeTure, M., Lin, W. L., Sanchez Contreras, M., Wojtas, A., Hinkle, K. M., et al. (2015). A novel tau mutation, p.K317N, causes globular glial tauopathy. Acta Neuropathol. 130, 199-214. doi: 10.1007/s00401-015$1425-0$

Thurston, V. C., Zinkowski, R. P., and Binder, L. I. (1996). Tau as a nucleolar protein in human nonneural cells in vitro and in vivo. Chromosoma 105, 20-30. doi: $10.1007 / \mathrm{bf} 02510035$

Trinczek, B., Biernat, J., Baumann, K., Mandelkow, E. M., and Mandelkow, E. (1995). Domains of tau protein, differential phosphorylation and dynamic instability of microtubules. Mol. Biol. Cell 6, 1887-1902. doi: 10.1091/mbc.6. 12.1887

van Herpen, E., Rosso, S. M., Serverijnen, L. A., Yoshida, H., Breedveld, G., van de Graaf, R., et al. (2003). Variable phenotypic expression and extensive tau pathology in two families with the novel tau mutation L315R. Ann. Neurol. 54, 573-581. doi: 10.1002/ana.10721

van Swieten, J. C., Bronner, I. F., Azmani, A., Severijnen, L. A., Kamphorst, W., Ravid, R., et al. (2007). The DeltaK280 mutation in MAP tau favors exon 10 skipping in vivo. J. Neuropathol. Exp. Neurol. 66, 17-25. doi: 10.1097/nen. 0b013e31802c39a4

Varani, L., Hasegawa, M., Spillantini, M. G., Smith, M. J., Murrell, J. R., Ghetti, B., et al. (1999). Structure of tau exon 10 splicing regulatory element RNA and destabilization by mutations of frontotemporal dementia and parkinsonism linked to chromosome 17. Proc. Natl. Acad. Sci. U S A 96, 8229-8234. doi: 10. 1073/pnas.96.14.8229

Varela, M. C., Krepischi-Santos, A. C., Paz, J. A., Knijnenburg, J., Szuhai, K., Rosenberg, C., et al. (2006). A 17q21.31 microdeletion encompassing the MAPT gene in a mentally impaired patient. Cytogenet. Genome Res. 114, 89-92. doi: $10.1159 / 000091934$

Violet, M., Delattre, L., Tardivel, M., Sultan, A., Chauderlier, A., Caillierez, R., et al. (2014). A major role for Tau in neuronal DNA and RNA protection in vivo under physiological and hyperthermic conditions. Front. Cell Neurosci. 8:84. doi: $10.3389 /$ fncel.2014.00084

Vogelsberg-Ragaglia, V., Bruce, J., Richter-Landsberg, C., Zhang, B., Hong, M., Trojanowski, J. Q., et al. (2000). Distinct FTDP-17 missense mutations in tau produce tau aggregates and other pathological phenotypes in transfected CHO cells. Mol. Biol. Cell 11, 4093-4104. doi: 10.1091/mbc.11. 12.4093 
von Bergen, M., Barghorn, S., Li, L., Marx, A., Biernat, J., Mandelkow, E. M., et al. (2001). Mutations of tau protein in frontotemporal dementia promote aggregation of paired helical filaments by enhancing local beta-structure. J. Biol. Chem. 276, 48165-48174.

Wei, Y., Qu, M. H., Wang, X. S., Chen, L., Wang, D. L., Liu, Y., et al. (2008). Binding to the minor groove of the double-strand, tau protein prevents DNA from damage by peroxidation. PLoS One 3:e2600. doi: 10.1371/journal.pone. 0002600

Weingarten, M. D., Lockwood, A. H., Hwo, S. Y., and Kirschner, M. W. (1975). A protein factor essential for microtubule assembly. Proc. Natl. Acad. Sci. U S A 72, 1858-1862. doi: 10.1073/pnas.72.5.1858

Wischik, C. M., Novak, M., Thøgersen, H. C., Edwards, P. C., Runswick, M. J., Jakes, R., et al. (1988). Isolation of a fragment of tau derived from the core of the paired helical filament of Alzheimer disease. Proc. Natl. Acad. Sci. U S A 85, 4506-4510. doi: 10.1073/pnas.85.12.4506

Yoshida, H., Crowther, R. A., and Goedert, M. (2002). Functional effects of tau gene mutations deltaN296 and N296H. J. Neurochem. 80, 548-551. doi: 10. 1046/j.0022-3042.2001.00729.x

Yu, D., LaPointe, N. E., Guzman, E., Pessino, V., Wilson, L., Feinstein, S. C., et al. (2014). Tau proteins harboring neurodegeneration-linked mutations impair kinesin translocation in vitro. J. Alzheimers. Dis. 39, 301-314. doi: 10 3233/JAD-131274

Zarranz, J. J., Ferrer, I., Lezcano, E., Forcadas, M. I., Eizaguirre, B., Atarés, B., et al. (2005). A novel mutation (K317M) in the MAPT gene causes FTDP and motor neuron disease. Neurology 64, 1578-1585. doi: 10.1212/01.wnl.0000160116. 65034.12

Zempel, H., and Mandelkow, E. (2014). Lost after translation: missorting of Tau protein and consequences for Alzheimer disease. Trends Neurosci. 37, 721-732. doi: 10.1016/j.tins.2014.08.004

Conflict of Interest Statement: The authors declare that the research was conducted in the absence of any commercial or financial relationships that could be construed as a potential conflict of interest.

Copyright (c) 2015 Rossi and Tagliavini. This is an open-access article distributed under the terms of the Creative Commons Attribution License (CC BY). The use, distribution and reproduction in other forums is permitted, provided the original author(s) or licensor are credited and that the original publication in this journal is cited, in accordance with accepted academic practice. No use, distribution or reproduction is permitted which does not comply with these terms. 